\title{
A IDEIA DO NOVO CONSTITUCIONALISMO LATINO AMERICANO E A POSIÇÃO BRASILEIRA
}

\author{
Gabriela Brito Ferreira*1 \\ Victor Sales Pinheiro* ${ }^{2}$
}

\begin{abstract}
Resumo: O presente trabalho teve o objetivo apresentar a ideia e os pontos essenciais do Novo Constitucionalismo da América Latina fazendo o link com a posição do Brasil dentro dessa teoria constitucional. Utilizando de uma abordagem de pesquisa bibliográfica qualitativa acerca do Novo Constitucionalismo Andino, pautando-se em livros e artigos de Antônio Carlos Wolkmer. Com isso, responde-se em que medida, as nuances do Novo Constitucionalismo Latino-Americano podem alcançar a Constituição de 1988. Foi feita também uma distinção entre o Neoconstitucionalismo europeu e o Novo Constitucionalismo Latino-Americano, bem como buscou-se demonstrar a visão que Wolkmer sustenta sobre a Constituição brasileira.
\end{abstract}

Palavras-chave: Novo Constitucionalismo; Ciclos Constitucionais; Constituição brasileira; Multiculturalismo; Pluralismo Jurídico.

\section{THE IDEA OF THE NEW LATIN AMERICAN CONSTITUTIONALISM AND THE BRAZILIAN POSITION}

\begin{abstract}
The present work aims to present the idea and the essential points of the Latin American New Constitutionalism linking Brazil's condition within this constitutional theory. Using a qualitative bibliographical research approach about the New Andean Constitutionalism and based on books and articles by Antonio Carlos Wolkmer. The answer is to what extent the Latin American New Constitutionalism can reach the brazilian Constitution. A distinction was also made between European Neoconstitutionalism and New Latin American Constitutionalism, as well as the work has the focus to show the vision that Wolkmer maintains about the Brazilian Constitution.
\end{abstract}

Keywords: New Constitutionalism; Constitutional cycles; Brazilian constitution; Multiculturalism; Legal pluralism.

\footnotetext{
${ }^{1}$ Mestranda em Direito, políticas públicas e desenvolvimento Regional pelo Centro Universitário do Estado do Pará (CESUPA), graduada em Direito pelo Centro Universitário do Estado do Pará (CESUPA). Membro dos grupos de pesquisa (CNPQ): Democracia, Poder Judiciário e Direitos Humanos; Razão Pública, Secularização e Direitos Humano (CNPQ); Atuou como monitora na disciplina Sociologia Jurídica (2015) e na disciplina Filosofia do Direito (2018). Endereço: Passagem Santa Rita, no 49, Marambaia, Belém/PA, Brasil. Email: gabrielabf04@gmail.com. Cel: 91981664795.

${ }_{2}^{2}$ Professor Adjunto da Universidade Federal do Pará (UFPA) e do Centro Universitário do Pará (CESUPA), na graduação e pós-graduação. Coordenador dos Grupos de Pesquisa (CNPq) "Tradição da Lei Natural" e Razão pública, secularização e direitos humanos: casos, princípios e teorias políticas. Doutor em Filosofia pela UERJ (Tese sobre Heidegger e Platão). Mestre em Filosofia pela PUC-RIO (Dissertação sobre a República de Platão). Graduado em Direito no Centro Universitário do Pará. Site: www.dialetico.com.br. Endereço: Mundurucus n. 984, ap. 1104. Jurunas. Cep.66035-360. Belém/PA, Brasil. Email: professor@ dialetico.com.br. Cel: 91981160885.
} 


\section{INTRODUÇÃO}

Este trabalho terá como objetivo demonstrar as principais nuances acerca do Novo Constitucionalismo Latino Americano, principalmente no que pauta a diferença entre o Novo Constitucionalismo da América latina e o Neoconstitucionalismo Europeu.

Para tanto, especificará os lugares de origem de ambas as teorias e nos fundamentos que as pautam, destinando a primeira seção do artigo a esse trabalho. Determinando que o Neoconstitucionalismo será pautado em um terreno principiológico, bem como seu fundamento primeiro é a dignidade da pessoa humana, essa teoria preocupação com os direitos individuais a serem respaldados depois da segunda guerra mundial.

Já em relação ao Novo Constitucionalismo Andino, será utilizado os textos do principal expoente brasileiro Antônio Carlos Wolkmer, além de Dalmau e Fajardo os quais encabeçam as explicações sobre está teoria.

Portanto, estabelece que o Novo Constitucionalismo é pautado em um pluralismo jurídico advindo do reconhecimento das mais diversas culturas integrantes dos países latinoamericanos, além de ter como fundamento o construto histórico destes povos que justifica a existência de uma teoria constitucional distinta.

Passando pelos conceitos de multiculturalidade, interculturalidade e plurinacionalidade. Conceitos estes, que serão fonte para discernir a percepção dos ciclos constitucionais e quais constituições podem ser encaixadas em qual posição.

Dessa forma, a segunda seção do artigo se debruçará na análise dos ciclos do Novo Constitucionalismo Latino Americano e na posição da Constituição brasileira frente a este modelo constitucional e o modelo Neoconstitucional Europeu, assim como a posição do Luiz Roberto Barroso sobre essa situação.

Indo por fim, a terceira seção que será a análise dos dispositivos constitucionais que confirmam a posição de Wolkmer acerca do constitucionalismo brasileiro, verificando os artigos 231 e 231 da Constituição de 1988.

Com isto posto, o artigo buscará solucionar a questão: em que medida, as nuances do Novo Constitucionalismo da América Latina podem influenciar os dispositivos da Constituição de 1988, do mesmo modo que em qual posição o Brasil se encontra. 
Para tal, o artigo utilizará de metodologia bibliográfica qualitativa, usando livros e artigos, além da Constituição para construir um argumento e um estudo sobre o Novo Constitucionalismo Latino-Americano.

\section{NEOCONSTITUCIONALISMO E O NOVO CONSTITUCIONALISMO LATINO AMERICANO}

\subsection{O Novo Constitucionalismo Latino Americano}

O Novo Constitucionalismo Latino Americano é um fenômeno que surge especificamente na América latina, tendo como base o seu construto histórico, no qual todos os momentos políticos e exploratórios, desde a colonialidade até as ditaduras, moldaram as Constituições latino-americanas para que essas garantissem um grande número de direitos e liberdades individuais, bem como a proteção de direitos coletivos abrindo a porta para a consolidação das diversas culturas que reside nesses países.

Segundo Wolkmer (2001), esse fenômeno irá surgir do chamado pluralismo jurídico, aqui não visto como pluralismo apenas de normas e regras, mas sim como o pluralismo das culturas pertencentes as soberanias Andinas, portanto também o Novo Constitucionalismo Latino Americano é chamado de Andino, uma vez que se apresentou primeiramente nos países da cordilheira dos Andes.

A partir da pluralidade cultural, é possível verificar também uma pluralidade de regras e normas, o que leva a exclusão da corrente do monista, visto que ele não suporta as necessidades de uma sociedade que por si só carece de mecanismos para viabilizar a existência de forma respeitosa de suas características plurinacionais.

\footnotetext{
Pluralismo no Direito tende a demonstrar que o poder estatal não é a fonte única e exclusiva de todo o Direito, abrindo escopo para uma produção e aplicação normativa centrada na força e na legitimidade de um complexo e difuso sistema de poderes, emanados dialeticamente da sociedade, de seus diversos sujeitos, grupos sociais, coletividades ou corpos intermediários. (WOLKMER, 2010, p. 145).
}

Um dos principais expoentes brasileiros desse movimento, Antônio Carlos Wolkmer, releva em seus textos, tais como, "Pluralismo e Crítica do Constitucionalismo na América Latina”, o contexto social gerador do Novo Constitucionalismo da América Latina traçando o liame com as respectivas mudanças e evoluções.

Esse fenômeno traz em seu íntimo mudanças significativas em relação à estruturação e modificação de poderes Estatais, sendo essas, enfáticas nas organizações e distribuição desses 
mesmos poderes, como também, uma participação abrangente popular nas tomadas de decisão. Ele também enfatiza em tutelar os direitos fundamentais, de igual modo, a integração das camadas sociais nas tomadas de decisões políticas.

Portanto, voltou-se a esclarecer sobre o que é o Novo Constitucionalismo, bem como a pluralidade de fontes encontradas nos Países da América Latina, e demonstrando de forma acentuada o contexto social como base de formação desse fenômeno. É necessário aqui ser feita a diferenciação conceitual para evitar-se uma confusão muito comum que é a que existe entre o Neoconstitucionalismo e a tomada do Novo Constitucionalismo.

\subsection{As diferenças do Novo Constitucionalismo Andino e o Neoconstitucionalismo}

As primeiras nuances do Neoconstitucionalismo europeu, surgem no pós-guerra, pois com ela, veio a necessidade de garantir direitos as pessoas que sofreram o horror deste momento histórico. Logo, a necessidade de constitucionalizar e assegurar a proteção destes direitos no texto supremo se tornou eminente.

O fundamento primeiro do Neoconstitucionalismo, reside na ideia de dignidade da pessoa humana, de forma que a Constituição deve assegurar e desenvolver o direito do país nesta direção. Esta corrente também, traz a principiologia como fonte de direitos.

De acordo com Alves (2012, p. 137 e 138), o Neoconstitucionalismo retém consigo outras características que devem ser levadas em consideração, tais como: a) pragmatista - a nomenclatura dependerá de como se utiliza determinado direito; b) ecletismo metodológico a união entre a interpretação e aplicação do direito utilizando da hermenêutica analítica, para que o sistema possua uma lógica e coerência; c) estatalismo garantista; d) pós-positivismo; e) juízo de ponderação - partindo do ponto que estão banhados em princípios; f) conceito não positivista do direito - único meio de dar uma interpretação também pautada na moral.

O Neoconstitucionalismo é a ruptura do constitucionalismo liberal de previsão meramente formal de direitos. É a tentativa de garantia material de direito fundamentais para todos. (ALVES, 2012, p. 139).

O Novo Constitucionalismo Latino-Americano, em contraponto, é um modificador das Constituições, o direito vem da luta histórica dos países, ou seja, emana especificamente da vontade dos povos. 
O Novo Constitucionalismo Latino-Americano, não com esse termo propriamente dito, porém, como um constitucionalismo social teve seus primeiros ares 1917 com a Constituição Mexicana, ampliando o conceito de cidadania (ALVES, 2012, p. 140).

Rúben Martínez Dalmau (2008, p. 266) traz em seu texto a existência deste Novo Constitucionalismo, novos elementos nos traz a possibilidade de enfrentar de uma nova hipótese constitucional nos países latino americanos, é a existência de um novo constitucionalismo Andino, ele não só é diferente do constitucionalismo regional, mas também dos demais constitucionalismo, que até hoje, foram mais influentes nos países sulamericanos.

Este fenômeno também possui características especificas, como a de possuir Constituições extremamente extensas, tendo um grande número de artigos e esses demonstram a sociedade que os desenvolveram, em verdade essas constituições tendem a possuir essa extensividade pela necessidade da clareza no que pesa a proteção dos direitos. Ele irá buscar a participação popular pautada na ideia de soberania popular e usa a constituição como a peça centra em seu ordenamento. (Alves, 2012).

Pode-se destacar como características deste novo constitucionalismo, as seguintes ideias.

Efetiva participação popular: O poder constituinte deve observar a efetiva participação popular, respeitando as pluralidades nacionais, ou seja, é necessário que todas as pessoas de cada nacionalidade que formam aquele país agora plural, efetivamente votem, ou participem por outro mecanismo, como por exemplo, sejam ouvidos em suas comunidades, para que sejam editadas as leis. Inicialmente, não haveria somente participação em assembleias por meio de representantes, mas sim uma Democracia Participativa (BRANDÃO, 2015).

Integração das plurinacionalidades: No contexto do Novo Constitucionalismo LatinoAmericano em Países de terceira fase, ou terceiro ciclo, acontece a integração e cooperação das diversas nacionalidades. Como nessa fase o País em questão não possui uma nacionalidade única, mas diversos povos, todos devem ser necessariamente ouvidos. Trazendo assim, como objetivo principal ouvir essas diferentes nacionalidades e, portanto, permitir a sua participação nos processos de construção de decisões políticas (BRANDÃO, 2015).

Linguagem acessível a todos: Como existe essa plurinacionalidade e o objetivo é a sua integração no contexto nacional, faz-se necessário, que a Constituição seja acessível para todos os componentes deste País. Com isso, é importante que a linguagem seja sucinta e clara, 
reconhece-se a grande diversidade de linguagens, e permite-se a sua ampla tradução para contemplar essa diversidade (BRANDÃO, 2015).

Isso pode ser observado no art. $5^{\circ}$ da Constituição Boliviana, em que se exige que os atos Estatais sejam difundidos em ao menos dois idiomas oficiais do País, admitindo a existência da multiplicidade de idiomas encontrados em uso:

\begin{abstract}
Art 5: I- São idiomas oficiais do Estado o castelhano e todas as línguas originárias das nações e povos indígenas, que são os aymaras, araona, baure, bésiró, canichana, cavine, cayuba, chácobo, chimán, ese ejja, guarani, guarasu'we, guarayu, itonama, leco, machajuyai-kallawaya, machineri, maropa, mojeno-trinitario, mojeñoignaciano, mais, mosetén, movima, pacawara, puquina, quechua, siriono, tacana, tapiete, toromona, uru-chipaya, weenhayek, yaminawa, yuki, yuracaré e zamuco.

II. O governo plurinacional e os governos departamentais devem usar pelo menos dois idiomas oficiais. Um deles deve ser espanhol e o outro será decidido levando em conta o uso, a conveniência, as circunstâncias, as necessidades e as preferências da população como um todo ou do território em questão. Os outros governos autônomos devem usar as línguas de seu território e um deles deve ser o espanhol. (Tradução Nossa), (CONSTITUIÇÃO DA BOLIVIA, 2009).
\end{abstract}

É necessário observar neste ponto a liberação do poder contramajoritário, no sentido de viabilizar a defesa das minorias, visto que não haverá espaço no contexto do Novo Constitucionalismo Latino-Americano, que lidará com a elevação dos direitos participativos, ou seja, com a ascensão de poderes individuais, tornar-se-á desnecessário um controle contramajoritário tão atuante, pois cada cidadão será ouvido e atendido por outros poderes relativos.

\title{
3 POSIÇÃO DO BRASIL FRENTE AO NOVO CONSTITUCIONALISMO AMERICANO
}

\subsection{Conceitos do Novo Constitucionalismo da América Latina}

Para compreender a posição das Constituições dos países latino-americanos é necessário levar em consideração três conceitos basilares: o multiculturalismo, intercuturalidade e a plurinacionalidade.

O multiculturalismo traz o reconhecimento das demais culturas, onde essas não serão taxadas de não evoluídas ou em qualquer grau comparativo com as demais, mas em verdade, são culturas que possuem sua própria diversidade e suas distinções que devem ser exaltadas e preservadas, aqui não irá buscar a modificação das culturas mas sim a sua valorização e a consequente integração. 
O multiculturalismo está diretamente relacionado com alguns fenômenos que são colocados às "sociedades da modernidade tardia". O primeiro deles é a globalização. Esse fenômeno está associado a transformação e à aceleração das relações econômicas, industriais e financeiras, dos meios de comunicação e de transporte e das tecnologias, levando-os a atingir escalas globais. (ZORZI, 2012, p. 30).

Nesse ponto, é necessário que se estabeleça a diferenciação entre o universalismo e o relativismo. No universalismo temos que o ser humano possui o mesmo valor à frente de todos os Estados, o homem possui valor tanto intrínseco independente de seu gênero, idade, quantidade de renda que possui, ou posição social que possua, traz a ideia de direitos universais que independem de cultura, e por seu caráter unicamente humano devem ser respeitados.

Já no relativismo, tem-se a ideia que cada cultura tem sua particularidade e deve ser respeitada e preservada dentro de suas próprias nuances, mesmo que essas práticas sejam consideradas nefastas ou problemáticas para as demais culturas. No relativismo, não há um direito único. De acordo com o relativismo moral, não existe nenhum modelo que pode ser compatível universalmente, esse pensamento aceita o relativismo moral e diz que para cada cultura existe a sua própria perspectiva moral e, portanto, uma cultura com moral diferente não pode impor seus conceitos sobre as demais.

O multiculturalismo é o estudo de como se dá a coexistência das diversas culturas existentes em um único Estado, sendo a forma como devem ser vistas as diversas relações culturais que existem nos países. Dentro do contexto do multiculturalismo, vê-se a transformação de grupos que anteriormente eram considerados minorias em sujeitos manifestantes da diversidade cultural (ZORZI, 2012).

Já a interculturalidade possui sua especificidade própria e não pode ser confundida com o multiculturalismo, ela tem como foco comunidades emergentes, portanto, que estão em constante evolução e tomando foco; essas comunidades tendem a se reconhecer e valorizar suas próprias diferenças culturais (WOLKMER, 2006).

Nelas, há um discurso inovador que é assimilado em um processo social e histórico, ou seja, primeiro é necessário que sejam entendidos os contextos em que estão essas Constituições e sua posterior interação cultural.

É nesse momento que demonstra a existência de uma diferença entre cultura a nacionalidade, em uma nacionalidade há uma diversidade de culturas, nela é estipulada a ideia de pertença a um País, que possui diversos povos com suas próprias culturas. Como o Brasil, por exemplo, que é um país de grande dimensão territorial, logo possui inúmeras culturas, 
etnias e até línguas, porém, como a América latina facilmente expõe, não é necessário que um país tenha uma imensa dimensão territorial para abarcar uma vasta diversidade cultural.

Enquanto no multiculturalismo tem-se o reconhecimento dessa diversidade cultural, na interculturalidade, vai-se além do reconhecimento, dando poder a cada comunidade.

O primeiro ponto a ser estabelecido é o da identidade, cada cultura, cada povo assume sua própria identidade que deve ser preservada, essa identidade é a característica que os diferencia dos demais.

$\mathrm{Na}$ interculturalidade, tem-se o foco nas diversas identidades das culturas daqueles países. O segundo ponto é o da não homogeneidade traz um caráter de agregação cultural, ou seja, não existe apenas uma única cultura no país, sendo assim ele é homogêneo.

O terceiro e último é a diversidade cultural que já é trazida do primeiro ciclo do Novo Constitucionalismo junto com o multiculturalismo.

A interculturalidade não visa mais somente ao reconhecimento inicial das culturas, mas à integração entre elas, ou seja, busca que as diversas culturas possuam os mesmos pesos nas decisões do país e com isso elas possuam valores característicos de importância igualados perante o seu Estado. Dentre esses valores busca a satisfação dos Direitos Humanos, da cidadania e principalmente a busca pela paz (WOLKMER, 2006).

A não homogeneidade não é posta como transformação das demais culturas em uma, todavia, possui com o objetivo a inclusão cultural ao todo social. Busca a equitatividade entre as demais culturas de forma justa e solidária; essas culturas serão vistas de forma horizontal, ou seja, sempre buscando manter o peso.

Ela se apresenta no segundo ciclo ou segunda fase do Novo Constitucionalismo Latino Americano, justamente por não somente reconhecer, mas por fomentar o diálogo cultural dentro dos Países. É necessário dizer que a interculturalidade tem um difícil acesso justamente por existir essa grande diversidade.

Ela possui três aspectos importantes. O primeiro deles é o da tentativa de negociação entre essas culturas, pois existem vontades e desejos conflitantes. O segundo aspecto se interrelaciona com o da negociação e empatia, em que as diferentes culturas andinas se nivelam e se enxergam como mutuamente importantes, esse é um meio que facilita a negociação. $\mathrm{O}$ terceiro e último é a descentralização cultural, a Constituição passa a atribuir direitos às demais de forma que todas possuam atuação, bem como serve de reflexão para quais direitos e deveres devem ser postos em foco. 
Necessitamos inventar a democracia no sentido intercultural e o Estado no sentido plurinacional, porque o estado liberal moderno não retornará. Sua crise é irreversível e, portanto, o pior que nos pode acontecer é não conseguir viver este período com grande intensidade democrática e com um sentido mais profundo e inclusivo do que é a Bolivianidade (tradução nossa). (SANTOS, 2007, p.35).

O estado plurinacional busca a proteção e a possibilidade de que seus indivíduos vivam com suas próprias culturas, possuindo inúmeras identidades que não necessariamente venham ter relações entre si, podendo haver distinções marcantes entre culturas.

Ao contrário do disposto na interculturalidade, verifica-se a multiplicidade de efetivas nacionalidades dentro de um único país, a integração é elevada não só para comportar várias culturas, como para que elas não sejam vistas apenas como meras culturas aleatórias, mas sim como nacionalidades que juntas compõem um único país.

Esse quadro trazido pelas experiências constitucionais da Bolívia e do Equador provoca uma ruptura com o quadro posto pela teoria do Direito europeia ou teoria constitucional moderna, pois demonstra uma efetiva ideia de descolonização dos países latino-americanos e o devido deslocamento para a realidade social vivenciada nesses países.

Através da plurinacionalidade, engloba-se o que os constitucionalistas chamam de nova teoria da Constituição, inspirada justamente nas novas Constituições LatinoAmericanas. $\mathrm{O}$ estado plurinacional possui um caráter revolucionário, isso porque o Estado moderno vê a necessidade da formação de uma nacionalidade única que passaria a ser integrada pelas diversas culturas dentro de um determinado Estado. Essa nacionalidade se fortaleceria e ter-se-ia um novo conceito de Estado, porém, essa fase acaba por subjugar as diversas culturas, pois não há um destaque cultural, mas sim uma imposição de um modelo.

Esse Estado moderno nasce da intolerância de comportamentos culturais, como de religiosos, por exemplo, o Estado moderno promulga Constituições que trazem "receitas" que devem ser seguidas para obter a chamada nacionalidade, dentre elas, a língua oficial do país, com a qual os atos de governo devem ser redigidos, além disto, é imposto também uma única religião a ser seguida, esses atos são realizados sem considerar a diversidade interna. Dessa forma, vê-se que acontece uma mutação cultural, pois os indivíduos da sociedade são modificados para caber nos parâmetros impostos pelas receitas já determinadas.

Nesse sentido, a plurinacionalidade vem revolucionar, não demonstrando mais um único modelo posto no Estado moderno, mas sim, trazendo a possibilidade das diversidades entre nacionalidades que não limitariam as culturas. 


\subsection{Os três ciclos e a posição brasileira nestes}

Estruturalmente, Segundo Fajardo (2011) o Novo Constitucionalismo Latino Americano é dividido em ciclos, momento em que serão observadas questões de cunho social para a classificação das Constituições dos países latino-americanos, as quais serão marcados pelos conceitos visto no ponto anterior.

Os três ciclos do horizonte do constitucionalismo pluralista, são: a) constitucionalismo multicultural (1982-1988), b) constitucionalismo pluricultural (1989-2005) e c) constitucionalismo plurinacional (2006-2009), têm a virtude de questionar, progressivamente, elementos centrais da configuração e definição dos estados republicanos latino-americanos, elaborados no séc. XIX, e herança da tutela colonial indígena, propondo um projeto de descolonização a longo prazo (tradução nossa). (FARJADO, 2011, p. 2).

Portanto, estabelece que o primeiro ciclo é marcado pela a ideia do multiculturalismo e reconhece a diversidade cultural, observando a sua identidade e a multilinguagem, porém aqui ainda não é observado o pluralismo jurídico propriamente dito.

É neste ciclo, que verificamos a proteção da constituição sobre os direitos dos indígenas e quilombolas, os abrangendo como povos e comunidades tradicionais merecedores de preservação de sua cultura e de sua tradição.

Em alguns países que não tiveram o reconhecimento constitucional do pluralismo jurídico, entretanto, havia normas ou políticas secundárias, seja por causa de uma herança colonial antiga, seja por causa de fissuras intra-sistêmicas encorajadas pela Convenção 107 da OIT, que reconhecia justiça indígena, mas reduzida a resolução de conflitos menores entre os povos indígenas, com poderes não superiores aos da justiça de paz, conforme contemplado pela Lei de Comunidades Nativas de 1978 no Peru (tradução nossa).(FARJADO, 2011, p. 3).

No segundo ciclo, a palavra que dá característica é a interculturalidade, também dominado de Constitucionalismo pluricultural, e intensifica as diversidades culturais, nesse momento é visto o reconhecimento dessas culturas como fonte para o modelo de organização estatal.

A incorporação de novos direitos e poderes indígenas na sede constitucional, bem como a ratificação de tratados de direitos humanos que se tornaram parte do bloco constitucional, geraram, de alguma forma, uma inflação de direitos sem correspondência com mecanismos institucionais para torná-los efetivos. Tais mudanças constitucionais ficaram pendentes de uma tarefa ainda incompleta de revisão de toda a lei constitucional, administrativa, civil, penal, etc., para poder dar conta dos novos direitos e das atribuições públicas reconhecidas aos povos indígenas e demais coletivos (tradução nossa). (FARJADO, 2011, p. 3). 
O ciclo do pluriculturalismo, ou a interculturalidade dos povos traz a possibilidade da efetiva participação dessas culturas na formação do Estado. Neste ponto, há a descentralização do poder na mão de apenas um único governo, como também, a descentralização de um único modelo e o consequente repasse as diversas culturas componentes desse país. Essas diversidades são fundadas com a construções de novas Constituições e a efetiva demonstração de direitos assegurados conforme a sua realidade social. Essas Constituições não somente preveem como estabelecem possibilidades para a efetiva participação popular, não importando que classe ou etnia o cidadão pertenceria. A Constituição da Venezuela de 1999 é uma expoente deste ciclo.

Por último, o terceiro ciclo denominado de Constitucionalismo plurinacional, é a total integração das culturas, mas não mais como apenas povos, e sim como nações unindo-se em uma nação maior, neste ciclo é encontrado a Constituição da Bolívia (2009) e a Constituição do Equador (2008).

Os povos indígenas são reconhecidos não apenas como "culturas diversas", mas como nações ou nacionalidades originais com autodeterminação ou autodeterminação. Ou seja, sujeitos políticos coletivos com o direito de definir seu destino, governam-se em autonomias e participam dos novos pactos de Estado, que se configuram assim como um "Estado plurinacional" (tradução nossa). (FARJADO, 2011, p. 16).

Neste ciclo, as Constituições preveem uma reestruturação estatal, para não mais captar somente as diversidades culturais, mas para garantir que haja a variedade de nacionalidades e que esses povos sejam vistos como detentores de poderes constituintes originais, vale ressaltar que não se tem mais a visão de poder derivado como era dado aos povos indígenas, mas sim, poder original.

Estas novas nações se unem para formar a Constituição que servirá para todos e, portanto, deve servir a todos os povos e culturas deste país. No terceiro ciclo do Novo Constitucionalismo Latino Americano todos os povos são considerados sujeitos constituintes.

Essas Constituições trazem em seu íntimo o pluralismo jurídico e tem o preceito descolonizador, possibilitando a igualdade entre as culturas antes não ouvidas e as ordinárias do país.

Ciente dessas particularidades, entre as duas teorias constitucional, a dúvida reside na posição que a magna carta de 1988 brasileira ocupa, entre as duas correntes constitucionais, uma vez que, ainda presente na América Latina a própria constituição demonstra princípios inerentes ao Neoconstitucionalismo, sendo fundada em buscas de direitos para o homem. 
Para Antônio Carlos Wolkmer (2010), essa afirmação é equivocada, possuindo uma opinião divergente, ele acredita que a Constituição Federal brasileira de 1988 seria na verdade uma Constituição do primeiro ciclo do Novo Constitucionalismo Latino-Americano. Como afirma:

Em suma, ainda que de forma limitada e pouco satisfatória, a Carta Política de 1988 contribui para superar uma tradição publicista liberal-individualista e socialintervencionista, transformando-se num importante instrumento diretivo propulsor para um Novo Constitucionalismo, de tipo pluralista e multicultural. (WOLKMER, 2010, p. 152).

Já para Luiz Roberto Barroso, o expoente predominante no Brasil é o Neoconstitucionalismo Europeu. Uma vez que, nossa Constituição está banhada de princípios implícitos e explícitos e proliferada de um decisionismo baseado em juízo de ponderação, além de termos um plano de Governo onde existe a predominância de uma Democracia representativa.

\begin{abstract}
Não prevaleceu a ideia, que teve amplo apoio na sociedade civil, de eleição de uma constituinte exclusiva, que se dissolveria quando da conclusão dos trabalhos. Ao revés, optou-se pela fórmula insatisfatória de delegação dos poderes constituintes ao Congresso Nacional, a funcionar, temporariamente, como constituinte, inclusive com a participação de senadores eleitos anteriormente à sua instalação, por se encontrarem no curso de seus mandatos de oito anos (BARROSO, 2010, p. 41).
\end{abstract}

Dessa forma, nota-se um impasse, se a Constituição brasileira de 1988 é na verdade parte do Novo Constitucionalismo ou ainda está afixada com o Neoconstitucionalismo. Perante isso o pensamento apresentado por Wolkmer (2010), pode ser interpretado como correto, de forma que o Brasil parece estar entrando nos conformes do primeiro ciclo do Novo Constitucionalismo Andino.

Levando em consideração as especificidades do primeiro ciclo do Novo Constitucionalismo Latino Americano, principalmente o que cabe a explicação do multiculturalismo, é possível observar que o Brasil abre portas para esse pensamento, uma vez que, reconhece que em seu país a outros tipos de culturas, principalmente ao que cabe a seu extenso território.

O Brasil, embora lastreado em princípios, começa a apresentar reconhecimento da diversidade cultural que possui, permitindo que o país seja laico, bem como permitindo a liberdade cultural.

Isso posto, é necessário admitir que a constituição brasileira, ainda que possua um sistema principiológico e que tenha como fundamento a dignidade da pessoa humana, 
demonstra em seus artigos, os quais analisaremos na próxima seção, características advindas de um construto histórico brasileiro.

\section{ANÁLISE DE DISPOSITIVOS CONSTITUCIONAIS}

Ao trazer a discursão acerca do marco epistêmico e metodológico é necessário levar em consideração o pluralismo, este designa uma multiplicidade nas formas de ação prática, e diversidade nos campos sociais ou culturais. Dentro disso é possível segundo Wolkmer verificar algumas características:

1) a autonomia, poder intrínseco aos vários grupos, concebido como independente
do poder central; 2) a descentralização, deslocamento do centro decisório para
esferas locais e fragmentárias; 3) a participação, intervenção dos grupos, sobretudo
daqueles minoritários, no processo decisório; 4) o localismo, privilégio que o poder
local assume diante do poder central; 5) a diversidade, privilégio que se dá à
diferença, e não à homogeneidade; e, finalmente, 6) a tolerância. (WOLKMER,
2010, p. 144).

Portanto, muitos desses princípios são vistos, tanto nos dispositivos da Constituição Federal de 1988, quanto nas decisões do Supremo Tribunal Federal, que é intérprete último das demandas contidas na magna carta. Como é o caso das cotas raciais, ou da decisão que permite que o fundo partidário seja destinado em certa porcentagem ao sexo com menos representatividade.

Wolkmer (2010, p. 149), afirma que as Constituições brasileiras anteriores contemplam em toda sua forma o monismo, isso significa na prática, que as formas de representação política eram feitas de modo conservador e rigoroso em prol da grande propriedade e na defesa do liberalismo econômico, já em relação ao direito civil, a expressão cidadania esvaziava o sentido.

A Constituição de 1934 possui o primeiro intuito pluralista e romper com o perfil monista anteriormente instaurado, através dela vemos a introdução de direitos sociais e econômicos, além de instaurar uma tradição republicana federativa, com isso a instauração da representação classistas. (WOLKMER, 2010, p. 150).

Posteriormente passamos por mais um momento de Constituições autoritárias, que afastaram mais uma vez a ideia de multiculturalidade no Brasil, até desembarcar na no texto Constitucional de 1988, embora ainda mantenha um certo perfil liberal e monocultural e analítico é um avanço e é instaurada em novo momento histórico brasileiro, o pós ditadura. (WOLKMER, 2010, p. 151). 
Os principais dispositivos destacados por Wolkmer (2010, p. 152), são referentes ao capítulo VIII da constituição de 1988, seu título é dos índios.

Art. 231. São reconhecidos aos índios sua organização social, costumes, línguas, crenças e tradições, e os direitos originários sobre as terras que tradicionalmente ocupam, competindo à União demarcá-las, proteger e fazer respeitar todos os seus bens.

$\S 1^{\circ}$ São terras tradicionalmente ocupadas pelos índios as por eles habitadas em caráter permanente, as utilizadas para suas atividades produtivas, as imprescindíveis à preservação dos recursos ambientais necessários a seu bem-estar e as necessárias a sua reprodução física e cultural, segundo seus usos, costumes e tradições.

$\S 2^{\circ}$ As terras tradicionalmente ocupadas pelos índios destinam-se a sua posse permanente, cabendo-lhes o usufruto exclusivo das riquezas do solo, dos rios e dos lagos nelas existentes.

$\S 3^{\circ} \mathrm{O}$ aproveitamento dos recursos hídricos, incluídos os potenciais energéticos, a pesquisa e a lavra das riquezas minerais em terras indígenas só podem ser efetivados com autorização do Congresso Nacional, ouvidas as comunidades afetadas, ficandolhes assegurada participação nos resultados da lavra, na forma da lei.

$\S 4^{\circ}$ As terras de que trata este artigo são inalienáveis e indisponíveis, e os direitos sobre elas, imprescritíveis.

$\S 5^{\circ}$ É vedada a remoção dos grupos indígenas de suas terras, salvo, "ad referendum" do Congresso Nacional, em caso de catástrofe ou epidemia que ponha em risco sua população, ou no interesse da soberania do País, após deliberação do Congresso Nacional, garantido, em qualquer hipótese, o retorno imediato logo que cesse o risco.

$\S 6^{\circ}$ São nulos e extintos, não produzindo efeitos jurídicos, os atos que tenham por objeto a ocupação, o domínio e a posse das terras a que se refere este artigo, ou a exploração das riquezas naturais do solo, dos rios e dos lagos nelas existentes, ressalvado relevante interesse público da União, segundo o que dispuser lei complementar, não gerando a nulidade e a extinção direito a indenização ou a ações contra a União, salvo, na forma da lei, quanto às benfeitorias derivadas da ocupação de boa fé.

$\S 7^{\circ}$ Não se aplica às terras indígenas o disposto no art. $174, \S 3^{\circ}$ e $\S 4^{\circ}$. (BRASIL, 2016).

Ao analisar o caput do artigo, partimos da afirmação primeiramente do reconhecimento de sua organização social, como foi demonstrado na seção anterior, é possível verificar que na ideia do multiculturalismo justamente é prezado que os países pertencentes a este ciclo reconheçam em sua extensão culturas diversas e a existência de que possuam uma organização deles.

Também é afirmado, os seus costumes, que são particulares, e, portanto, a tolerância deve ser exercitada, bem como as línguas desses grupos são diferenciadas e como um dos principais pilares de suas culturas devem ser preservadas, além de suas crenças e tradições.

Dessa forma, A constituição de 1988 vem trazendo o reconhecimento de uma pluralidade que antes não era preocupação dentro do Brasil, começa aí o reconhecimento e multiculturalidade verificada na carta constitucional. 
Por conseguinte, é possibilitada a proteção sobre as terras demarcadas pela a união desses grupos reconhecidos, isso possibilita, que sua cultura seja mantida intacta. Vale ressaltar, que ainda não há aqui a interculturalidade, apenas um reconhecimento e proteção destes indígenas o que nos leva a conclusão pelo primeiro ciclo do Novo Constitucionalismo Latino Americano.

Os demais parágrafos do artigo 231 são reforços para a ideia do caput, protegendo e dando total possibilidade de uso pelos índios de suas terras, não podendo ser removidos desta, bem como não se permite a desapropriação de terras indígenas.

Art. 232. Os índios, suas comunidades e organizações são partes legítimas para ingressar em juízo em defesa de seus direitos e interesses, intervindo o Ministério Público em todos os atos do processo. (BRASIL, 2016).

No artigo 232, é dado a legitimidade destes povos indígenas a pleitear, ou seja, possibilita o acesso à justiça por parte destes, além de colocar sobre a proteção do Ministério Público para que esse proteja os direitos e interesses se vierem a ser violados.

Ademias, não esteja propriamente no texto constitucional, vale ressaltar o artigo 68 do ADCT (ato das disposições constitucionais transitórias), que vem abarcar os direitos das comunidades tradicionais como os quilombolas.

Art. 68. Aos remanescentes das comunidades dos quilombos que estejam ocupando suas terras é reconhecida a propriedade definitiva, devendo o Estado emitir-lhes os títulos respectivos. (BRASIL, 2016)

Com ele é possível verificar, a garantia sobre as terras desta comunidade tradicional, podendo deduzir o reconhecimento também desta outra vertente cultural, permitindo que as suas tradições também venham a ser preservadas.

Com isso, é possível observar, que mesmo que o Brasil possua um constitucionalismo muito semelhante ao sustentado pela vertente do Neoconstitucionalismo europeu, é também possível verificar uma pluralidade que surge pela diferença cultural e pelo construto histórico por onde passa a história brasileira.

O Brasil possui nuances sobre o Novo Constitucionalismo da América Latina, e com ele o nascimento de uma ideia de multiculturalidade que permeiam discussões sobre a diferença cultural, principalmente no que se refere a extensão territorial brasileira.

\section{CONCLUSÃO}


O trabalho buscou esclarecer como surgiu e o fundamento do Novo Constitucionalismo da América Latina, explicando a ideia do pluralismo jurídico e da construção histórica desses países, que necessitaram de mais proteção pelas opressões vividas ao longo de sua existência, desde a colonialidade até as ditaduras e dominações vividas pelos povos aqui existentes.

Desta maneira, o Novo Constitucionalismo surge, como um meio novo de gerenciar as Constituições latino americanas, sendo assim, é um fenômeno advindo de uma pluralidade cultural gerada pelo pluralismo jurídico.

Isto posto, foi necessário fazer a diferença entre o Neoconstitucionalismo e o Novo Constitucionalismo Latino-Americano. O primeiro foi visualizado depois das grandes guerras graças a necessidade de proteção dos direitos dos europeus que sofreram com as consequências desses acontecimentos, e tem como base os princípios que irão nortear todo o texto constitucional, ele apresenta também como fundamento a Dignidade da pessoa humana, além de outras características voltadas para a proteção desses direitos.

O Novo Constitucionalismo Latino Americano, é pautado na pluralidade cultural e nas histórias dos países que o utilizam, além disso é marcado por textos constitucionais extensivos, ou seja, necessita de inúmeras explicações e textos prolongados para a garantia tanto de direitos individuais como de direitos coletivos, além de preservar o reconhecimento da diversidade nestes países.

O modelo constitucional latino-americano, também possui como marco uma maior participação popular nas decisões acerca do governo, além da integração das plurinacionalidades, isso mais visto nos países do terceiro ciclo e a linguagem acessível a todos, onde os países tendem a melhorar a comunicação, bem como reconhecer que os demais dialetos são importantes para a preservação das culturas.

Depois foi realizada a explicação dos ciclos deste modelo Constitucional, dando ênfase ao primeiro ciclo, onde é apontada a posição que a Constituição brasileira de 1988 se encontra, mesmo que essa apresente também características do Neoconstitucionalismo, possui nuances vindas de seu caminho histórico, assim como das culturas e povos diversificados que fazem parte deste país, possibilitando a multiculturalidade.

Como é afirmado no art. 231 da Constituição Federal é possível ver o reconhecimento do Estado brasileiro para com os indígenas, possibilitando e dando ferramentas a estes que prossigam em sua cultura, sem tentar modificá-la. 
Com isso, é possível ver o Brasil dentro do primeiro ciclo de Novo Constitucionalismo da América Latina, onde a Constituição Federal de 1988 é a primeira brasileira nesse sentido, embora ainda falte muito para reconhecimento de todos os direitos plenos das mais diversas culturas nesse grande território brasileiro.

\section{REFERÊNCIAS}

ALVES, Marina Vitório. Neoconstitucionalismo e Novo Constitucionalismo LatinoAmericano: características e distinções. Revista SJRJ, Rio de Janeiro, vol. 19, n. 23, p. 133145, ago. 2012.

BRANDÃO, Pedro. O Novo Constitucionalismo Pluralista Latino-Americano. $1^{\text {a }}$ edição. Lumen Juris, 2015.

BARROSO, Luís Roberto. Curso de direito constitucional contemporâneo: os conceitos fundamentais e a construção do novo modelo. 2. ed. São Paulo: Saraiva, 2010.

Neoconstitucionalismo e constitucionalização do Direito: o triunfo tardio do Direito Constitucional no Brasil. Revista Eletrônica sobre Reforma do Estado (RERE), Salvador, Instituto Brasileiro de Direito Público, mar-mai, 2007. Disponível em: http://jus.com.br/artigos/7547/neoconstitucionalismo-e-constitucionalizacao-do-direito. Acesso: em: 17 jul. 2017.

O Novo Direito Constitucional Brasileiro: contribuições para a construção teórica e prática da jurisdição constitucional no Brasil. $3^{\mathrm{a}}$ reimpressão. Belo Horizonte: Editora Fórum, 2014.

BOLÍVIA. Nueva Constitución Política del Estado, 2009. Disponível em: $<$ https://bolivia.infoleyes.com/norma/469/constituci\%C3\%B3n-pol\%C3\%ADtica-del-estadocpe>. Acesso em: 28 out. 2016.

BRASIL. Constituição da República Federativa do Brasil de 1988. Brasília, DF: Presidência da República, 2016. Disponível:

<http://www.planalto.gov.br/ccivil_03/constituicao/constituicao.htm>. Acesso em: 1 jan. 2019.

DALMAU, Rúben Martínez. El nuevo constitucionalismo latinoamericano y el proyecto de Constitución de Ecuador de 2008. In: Alter Justicia: estudos sobre Teoría y Justicia Constitucional, n. 1, año 2, Guayaquil, p. 17-27, 2008.

FAJARDO, Raquel Yrigoyen. Pluralismo jurídico, derecho indígena y jurisdicción especial en los países andinos. Revista El Otro Derecho, Bogotá: ILSA n. 30. p. 171-196. 2004. Disponível em: http://www.cejamericas.org/Documentos/DocumentosIDRC/128elotrdr03006.pdf. Acesso em: 30 nov. 2016. 
El horizonte del constitucionalismo pluralista: del multiculturalismo a la descolonización. In: El derecho en América Latina. Cesar Rodriguez Garavito (org). Siglo Veintiuno Editores, Buenos Aires, p. 139-160, 2011.

PASTOR, Roberto Viciano; DALMAU, Rubén Martínez. Necesidad y oportunidad en el proyecto venezolano de reforma constitucional (2007). Revista Venezolana de Economía y Ciencias Sociales, vol. 14, $n^{\circ}$ 2, p. 102-132, 2008.

Se puede hablar de un nuevo constitucionalismo latinoamericano como corriente doctrinal sistematizada? 2012. Disponível em: <http://www.juridicas.unam.mx/wccl/ponencias/13/245.pdf>. Acesso em: 28 jul. 2017.

EI nuevo constitucionalismo latinoamericano: fundamentos para una construcción doctrinal. Trabalho defendido no Congresso Mundial de Constitucionalistas, 2011. Disponível em:

<https://www.academia.edu/6339900/El_nuevo_constitucionalismo_latinoamericano_fundam entos_para_una_construccion_doctrinal>. Acesso em: 28 jul. 2017.

SANTOS, Boaventura de Sousa. La reinvención del Estado y El Estado plurinacional. Santa Cruz de La Sierra: Alianza Interistitucional CENDA/CEJIS/CEBID, 2007.

WOLKMER, Antônio Carlos; FAGUNDES, Lucas Machado. Para um novo paradigma de Estado Plurinacional na América Latina. Novos Estudos Jurídicos, v. 18, n. 2, p. 329-342, 2013. Disponível em: <http://siaiap32.univali.br/seer/index.php/nej/article/view/4683>. Acesso em: 14 set. 2017.

Pluralismo e Crítica do Constitucionalismo na América Latina. Academia brasileira de Direito Constitucional, 2010. Disponível em: <http://www.abdconst.com.br/revista3/antoniowolkmer.pdf>. Acesso em: 30 nov. 2016.

Pluralismo jurídico, direitos humanos e interculturalidade. Disponível em: $<$ https://periodicos.ufsc.br/index.php/sequencia/article/view/15095/13750>, 2006. Acesso em: 20 nov. 2016.

. Pluralismo Jurídico: fundamentos de uma nova cultura no Direito. 3. ed. São Paulo: Alfa-Omega, 2001.

. Tendências contemporâneas do constitucionalismo latino-americano: Estado plurinacional e pluralismo jurídico. Revista Pensar, Fortaleza, v. 16, n. 2, p. 371-408, 2011.

ZORZI, José Augusto. Estudos culturais e multiculturalismo: uma perspectiva das relações entre campos de estudo em Stuart Hall. Trabalho de conclusão de curso para obtenção de Licenciatura em História pela UFRG, 2012. 